\title{
O debate teórico da década de 1990: possibilidades analíticas para política externa
}

\author{
Aline Pavan dos Santos*
}

\begin{abstract}
Resumo
A década de 1990 representa um marco no Sistema Internacional pelo fim da bipolaridade que atingiu tanto as potências como os países em desenvolvimento. A este respeito, destaca-se o desenvolvimento teórico das Relações Internacionais que se mantiveram centradas na construção do papel dos EUA para o mundo e da reinserção dos demais Estados na Nova Ordem Mundial. A meta central do trabalho é a de verificar se as abordagens que surgem neste período são capazes de fundamentar solidamente a constituição do Sistema Internacional neste novo momento, bem como, se os novos vieses analíticos sugerem possibilidades distintas de avaliação da política externa dos Estados. Por fim, objetiva-se identificar pontos de contato entre as teorias, relacionados à ordem liberal, que neste momento constitui-se com força entre as nações.

Palavras-chave: Teoria de Relações Internacionais, política externa, pósGuerra Fria.
\end{abstract}

\section{Introdução}

A análise de política externa é recorrente no campo das Relações Internacionais e frequentemente executada através da interlocução entre dados históricos e a aplicação de modelos teóricos próprios da área para a compreensão dos diversos fenômenos, a este respeito Bobbio (1995, p. 15) diz que:

\begin{abstract}
Nunca considerei os dois métodos incompatíveis. Sempre pensei, ao contrário, que eles se integram reciprocamente. Quem trabalha com o método analítico nunca pode esquecer que a realidade é bem mais rica do que as tipologias abstratas, que devem ser continuamente revistas para dar conta dos novos dados ou de novas interpretações dos dados já conhecidos. Mas o historiador também deve se dar conta de que, para compreender, descrever e ordenar a realidade de fato revelada pelos documentos, não pode abrir mão de conceitos abstratos, cujo significado, saiba ou não, the é fornecido pelos fanáticos da análise.
\end{abstract}

Com a mesma perspectiva Halliday (1995) sublinha que os analistas desta temática não devem ser estritamente racionalistas nem se deixarem cair no

\footnotetext{
* Mestranda em Relações Internacionais pelo Programa San Tiago Dantas (UNESP, UNICAMP, PUC-SP). Email:apavan@ig.com.br.
} 
relativismo. Com estas balizas, o autor sugere que a história deve ocupar um lugar privilegiado nos estudos para que se possa problematizar os conceitos e desafiar o senso comum, já que mesmo com a emergência das mais distintas categorias teóricas ainda existem vácuos analíticos capazes de serem sanados apenas com a reconstrução de fatos.

A mesma visão é compartilhada ainda por Duroselle (2000) que alerta sobre os erros interpretativos que simplificações conceituais que se propõem a explicar um grande número de acontecimentos podem induzir. Com isso, aponta-se para uma possível inversão nos termos de estudo em que se parte das abstrações para avaliar acontecimentos, quando o indicado é que após mapear as nuances do objeto verifique-se se ele cabe em algum quadro de abordagem.

Nas ciências humanas as teorias costumam apresentar a reunião de diversos elementos de nosso conhecimento e Ihes atribuir uma relação de causalidade, ordenando-os através de estruturas cognitivas e quadros conceituais capazes de propiciar a investigação e formulação de hipóteses em torno do objeto. Em especial nas Relações Internacionais, Baillard (1990) identifica que as teorias podem assumir o caráter:

1- Essencialista: procura revelar a essência das entidades sociais e são demarcadas por um caráter normativo;

2- Empírico: partem de preposições gerais para explicar e ressaltar a previsibilidade dos fenômenos sociais;

3- Dialético-histórico: tomam consciência crítica da realidade e também participam dos fatos sociais.

Pela perspectiva de Cox (1986) as preposições teóricas não são apenas dialético-históricas como também direcionadas a um determinado público e legitimadoras de uma ordem. Com isso ressalta-se que as teorias não possuem um caráter neutro, pelo contrário, as visões servem para sustentar interesses e são funcionais às necessidades dos grupos dominantes, engajadas ao contexto histórico e político ${ }^{1}$. Tais preposições permitem dizer que as teorias são formuladas a partir de fatos históricos, fornecem abstrações e a partir do momento em que seu conjunto de

\footnotetext{
${ }^{1}$ Esta linha de pensamento é parte da Teoria Crítica de relações internacionais. Para aprofundamento ver Cox; Sinclair (1999).
} 
ideias passa a ser reproduzido se torna prescritivo e pode influenciar na tomada de decisão.

Postos tais marcos, o fim da Guerra Fria pode ser abordado como um momento particular e cujos desdobramentos impuseram desafios aos paradigmas analíticos existentes. Em geral, as visões que ganham destaque durante os anos 1990 vão dialogar criticamente e se colocarem como alternativas ao modelo mais representativo durante a vigência da disputa Leste $\mathrm{x}$ Oeste: o neorrealismo formulado por Kenneth Waltz.

Conceitualmente, o neorrealismo prevê uma análise estrutural da política internacional e cujos pressupostos são (Waltz, 1979):

1- Existência de uma estrutura anárquica que constrange a atuação dos agentes;

2- Sistema composto por unidades políticas especializadas em garantir a sobrevivência;

3- Diferenciação na distribuição das capacidades entre as unidades que definirá se o sistema é unipolar, bipolar ou multipolar.

A partir desta sistematização a estrutura e a composição do sistema são vistas como constantes e a única possibilidade de mudança reside na distribuição das capacidades entre os atores. Em decorrência a anarquia orienta a atuação das unidades políticas que para garantirem sua sobrevivência devem centrar seus esforços na defesa bem como formar alianças para contrapor as potências, o que em última instancia leva ao equilíbrio de poder. Ainda de acordo com o autor, esta tendência sistêmica ao equilíbrio de poder faz com que a bipolaridade seja a estrutura mais estável.

Dadas estas preposições iniciais e um panorama sobre a teoria neorrealista, se constituem como objetivos seguintes: contextualizar a ordem mundial da década de 1990 com destaque ao papel que os Estados Unidos (EUA) assumem e a tentativa de inserção dos países em desenvolvimento, apresentar uma revisão seletiva das propostas teóricas que compõe o mainstream ${ }^{2}$ do período sem necessariamente

\footnotetext{
${ }^{2}$ Ressalta-se que o critério para seleção das teorias aqui apresentadas remete-se às possibilidades que abrem ao entendimento do comportamento dos Estados no Sistema Internacional e que consideram fatores materiais, motivo pelo qual não serão abordadas as formulações pós-modernas.
} 
realizar uma incursão cronológica, e demarcar a contribuição que cada uma delas traz para o entendimento da política externa levada a cabo pelas nações.

\section{O Sistema Internacional pós-Guerra Fria}

A queda do Muro de Berlin em 1989 e o posterior colapso da União Soviética (URSS) em 1991 demarcaram o fim da Guerra Fria e o início de novos processos político-econômicos ao redor do mundo. Este período é fortemente marcado pelo antagonismo, não mais expresso em termos de comunistas e capitalistas, mas sim relativo à coexistência de processos homogeneizantes e fatos afirmativos da diversidade.

A primeira mudança significativa se verifica nos contornos do mapa mundial que apesar da reunificação alemã em 1990 apresentou o surgimento de outros 20 Estados soberanos em apenas dois anos (Halliday, 1994). Prova disto está refletida no sistema da Organização das Nações Unidas (ONU) que é fundada com 51 Estadosmembros em 1945, passando a 159 membros em 1989 e chegando, em 2011, a comportar 193 nações, grande parte delas advindas da ex-URSS e da descolonização africana e asiática ${ }^{3}$. Segundo Kissinger (2004, p. 806 - 807, tradução nossa) muitas das novas nações "se consolidam com um histórico diferente dos Estados europeus. [...] Para muitas delas, as fronteiras atuais representam apenas uma conveniência administrativa dos poderes imperiais" .

Como consequência da ineficiência dos contornos fronteiriços oficiais e a despeito do fim da corrida armamentista, a última década do século XX foi marcada pelo aumento da insegurança e o desencadeamento de uma série de conflitos armados. Dentre eles podemos destacar a Segunda Guerra do Golfo ${ }^{5}(1990-1991)$ e a

\footnotetext{
${ }^{3}$ Alguns dos países que surgiram com o desmembramento da URSS foram: Azerbaijão, Cazaquistão, Estónia, Geórgia, Letónia, Lituânia, Rússia e Ucrânia. Na África, os últimos Estados a se tornarem independentes foram Namíbia (1990) e Eritréia (1993).

4 No original: "have come into being, many of them quite different from the historic European nations state. [...] For many of them, the current borders represent the administrative convenience of the imperial powers." (Kissinger, 1994, p. 806 -807).

${ }^{5}$ A segunda Guerra do Golfo refere-se ao conflito entre Iraque e Kwait, também abordada como operação Tempestade no Deserto.
} 
guerra entre Armênia e Azerbaijão, ou ainda o Genocídio de Ruanda (1994), a guerra civil em Serra Leoa e a desagregação da lugoslávia.

Os exemplos supracitados não cobrem a totalidade de situações que ocorreram neste espaço de dez anos, contudo, nota-se que grande parte dos confrontos saiu dos moldes convencionais de enfrentamento entre Estados e trouxe a tona questões étnicas, religiosas e de desenvolvimento, que atrelados a natureza difusa dos beligerantes viria desafiar a agenda de segurança internacional e demonstrar a influência que problemas nacionais trariam para a cena externa. Encerrada a lógica bipolar, tais elementos se tornam desafiadores nas estratégias das potências já que elas terão que julgar os conflitos em que terão envolvimento e arcar com as consequências da interferência e da negligencia.

$\mathrm{Na}$ esfera política assistimos a continuidade da onda de democratização dos países latino-americanos iniciada nos anos 1980 e o fim do Apartheid na África do Sul em contraponto às repressões empreendidas pela China na Praça da Paz Celestial em 1989 bem como a adoção de regimes totalitários em grande parte dos Estados recém formados. No plano da política internacional, a proliferação das instituições já presenciada anos antes desponta discussões sobre governança e enfatiza a capacidade reduzida dos Estados em lidarem isoladamente com temas como meio ambiente, comércio e tráfico - seja de armas, drogas ou pessoas.

Não o bastante, a economia mundial deparou-se com a intensificação da internacionalização empresarial, acompanhada da formação de blocos econômicos regionais e do trânsito global de capitais. Para Silva (2008) estes processos estão ligados as mudanças econômico-tecnológicas iniciadas nos anos 1970 e constituem uma nova estratégia para a reestruturação capitalista mundial. Em grande medida, as restrições que se colocam à atuação dos Estados na regulamentação e controle destes fluxos abrem espaço para que o conceito de soberania no ambiente internacional seja revisado e para a cunhagem do termo globalização, que posteriormente irá adquirir dimensões que extrapolam à econômica. Há ainda que se destacar as crises locais que geraram impactos sistêmicos como ocorreu na Argentina e no México em 1994, na Ásia em 1997 e na Rússia em 1998. 
Apesar da percepção generalizada de que os EUA haviam vencido a Guerra Fria, o cenário imediato se caracterizou por indefinições quanto à configuração do Sistema Internacional e consequentemente da estratégia que deveria ser desenvolvida nele. Contudo, posturas otimistas sobre o futuro tornavam-se cada vez mais comuns e instintivamente referenciavam valores ligados a superpotência restante.

Um ponto chave para exacerbar este sentimento otimista foi a interferência da Organização das Nações Unidas (ONU) na segunda Guerra do Golfo. O conflito iniciouse com a invasão que o Iraque empreendeu sobre o Kwait a fim de anexar o território e as reservas petrolíferas do país vizinho. Sob a égide do Conselho de Segurança, deliberou-se a operação Tempestade no Deserto que impôs o recuo das tropas iraquianas e restaurou os antigos limites fronteiriços entre os beligerantes. $O$ mecanismo de resolução demonstrou que havia se encerrado o período de paralisia do Conselho de Segurança por causa de disputas entre as superpotências, assim como a resolução conseguiu legitimidade por estar amparada na Instituição e, por fim, dava sinais de que a participação democrática dos Estados na solução de assuntos internacionais seria daí por diante possível e desejável.

O acontecimento deu base para que o então presidente dos Estados Unidos George Bush (1989-1992) cunhasse o termo Nova Ordem Mundial como denominação da época de paz e prosperidade que estava sendo inaugurada. Na prática, esta concepção é resultante do triunfo da economia de mercado e se apoia ideologicamente no neoliberalismo, além de que dela parte o apontamento da superioridade do bloco Ocidental em termos produtivos e sociais, além de colocá-lo como universal e inevitável, capaz de solucionar os problemas econômicos e bélicos em longo prazo.

Apesar da força retórica que o termo ganhou, Ikenberry (1996) assinala que os EUA não precisavam construir uma nova ordem, pois o núcleo da que foi elaborada em 1945 mantinha-se válido e apoiado por seus integrantes. Segundo esta visão a queda do comunismo já demonstra a expansão da ordem Ocidental, que incorporaria os que Ihe faziam oposição no período bipolar mas com a manutenção das arenas multilaterais, da democracia e do capitalismo, sendo a tríade central e necessária a expansão dos interesses estadunidenses. Assim, os Estados Unidos não estariam 
desbravando novos horizontes, mas finalmente chegavam ao centro da ordem que estabeleceram há aproximadamente cinquenta anos antes.

Uma visão oposta considera que o pós-Guerra Fria é marcado por turbulências e transições, sem uma estrutura norteadora eficaz em que fatalmente se vivencia a nova desordem mundial (Vizentini, 1996). Tal incapacidade ordenadora é evidenciada pela falta de estratégia dos países em lidar com uma agenda diversificada e sem polarizações ideológicas claras, além da própria indefinição quanto aos polos de poder e da ascensão de assuntos internos dos Estados à categoria de internacionais como crises econômicas, o narcotráfico e os direitos humanos. Aqui os Estados Unidos aparecem como inaptos tanto a manterem o padrão político da bipolaridade quanto a inaugurarem novos meios de conduta.

Ainda assim, tanto na concepção de ordem como de desordem do Sistema Internacional, fato é que os EUA emergem como uma nação singular e vis ta por parte dos analistas como hegemônico em um momento unipolar e pelos demais como líder do arranjo multipolar. Essas variações interpretativas remetem as distintas visões do que significou o ruir da disputa Leste $\mathrm{x}$ Oeste e se constituem em teses sobre os arranjos de poder possíveis em um dado sistema.

Uma interpretação de destaque é a de Fukuyama (1989) que ressalta o otimismo liberal da época e vê no fim do bloco soviético o fim da história já que coloca um ponto final na dicotomia ideológica da humanidade e universaliza as democracias liberais do Ocidente. Para o autor, a vitória liberal já está concluída no campo das ideias e ainda que incompleta no mundo material, este acabará se constituindo à sua imagem. Tal versão não nega a ocorrência de conflitos, mas sim o desenvolvimento de sistemas político-econômicos contraditórios ao padrão liberal.

Esta tese recebe críticas que reforçam a validade analítica do Marxismo apesar do fim da experiência soviética e apontam para a possibilidade de surgimento de novos paradigmas ${ }^{6}$. Anos depois, o próprio Fukuyama (1999) revisa suas afirmações e refuta que a história tenha chegado ao fim dada a contínua possibilidade de produção do conhecimento e o reconhecimento dos limites práticos à expansão do modelo de

\footnotetext{
${ }^{6}$ Para uma revisão das críticas ver: BURNS, T (org.). After History: Francis Fukuyama and His Critics. Lanham: Rowman and Littlefield, 1994.
} 
livre comércio e da democracia, de modo que ambos não são mais vistos como endógenos.

Entretanto, mesmo neste segundo momento é reiterada a perspectiva de que o progresso tecnológico e científico criado pelo capitalismo o mantém como viável e com capacidade de expansão mundial, sendo que no segundo caso são necessários percussores como o governo dos EUA e as instituições financeiras internacionais. Nas palavras de Fukuyama (1999, p.1, tradução nossa) "nada do que tem acontecido no mundo político ou na economia global nos últimos dez anos desafia, a meu ver, a conclusão de que as democracias liberais e a ordem econômica de livre mercado são as únicas opções viáveis para as sociedades modernas" ${ }^{\prime 7}$.

Halliday (1994, p. 60) converge parcialmente com as ideias propostas por Fukuyama ao afirmar que variações de socialdemocracia são subsistentes e estão cada vez mais circunscritas pela falta de alternativa ao capitalismo, mas alerta que "embora - modelo autoritário de esquerda tenha sido desacreditado, a ideia de que a democracia nos moldes americano- europeu é o mais desejado está longe de conseguir a unanimidade entre os Estados capitalistas".

Outro ponto destacado é o de que uma ordem internacional homogênea prevê o compartilhamento de normas, tanto internas como interestatais. Com a perda da importância estratégica das nações emergentes, a aceitação de certas normas internacionais passa a ser uma necessidade por parte destes Estados que são compelidos à adesão e às adequações internas que se seguem, de modo que se paga um alto preço em ambas as decisões (Halliday, 1994). Exemplo claro das distorções geradas por estes acordos é vista na trajetória da América Latina que avança na adoção da democracia e do livre mercado, mas padece por vulnerabilidades econômicas e sociais.

Também crente na capacidade de expansão do poderio dos EUA, Nye (2002) define as distintas nuances de exercício de poder e apresenta a tese sobre o Poder Brando (Soft Power) para reiterar a necessidade de que a Nação não reine apenas por suas capacidades bélicas e econômicas, mas principalmente pelo prestigio de seus

\footnotetext{
${ }^{7}$ No original: "Nothing that has happened in world politics or the global economy in the past ten years challenges, in my view, the conclusion that liberal democracy and a market-oriented economic order are the only viable options for modern societies." (Fukuyama, 1999, p. 1).
} 
valores, de suas instituições e de sua cultura. Em outros termos, a preocupação do autor é a de que a liderança estadunidense no Sistema Internacional seja legitima e menos custosa na medida em que reduz o uso de coerções e incorpora fatores culturais às negociações, de modo que seus valores assumem imperativos morais e deixam de ser apenas aceitos para se tornarem desejados. Tal panorama vislumbra que com o fim da disputa ideológica com a URSS o momento é oportuno para a disseminação e fortalecimento do pensamento ocidental estadunidense.

Sob outro prisma, Todd (2003) afirma que queda da URSS alimentou apenas uma ilusão do fortalecimento dos EUA, já que materialmente a nação está cada vez mais dependente do abastecimento externo e convive com um déficit comercial que cresce exponencialmente. Associado a estes fatores, Todd confere destaque a incapacidade dos estadunidenses em criarem uma identidade com os povos "conquistados", já que restringem a aceitação de culturas diferentes e travam guerras mesmo em situações de enormes disparidades de poder, o que Ihes mina qualquer possibilidade de legitimação.

Na mesma linha, há trabalhos que destacam o aspecto econômico para demonstrar a alternância das potências ao longo dos séculos e reiteram que gradualmente o poder dos EUA está diminuindo e sua liderança será substituída no Sistema Internacional (Arrighi, 1996; Kennedy, 1989). Mais enfaticamente, Huntington (1993) simboliza o pessimismo sobre a possibilidade de expansão das ideias e dos modelos sociais dos Estados Unidos ao afirmar que os conflitos existentes no pós Guerra Fria são motivados em grande medida por divergências culturais, portanto, o expansionismo da ideologia Ocidental sobre as mais diversas culturas tende a agravar os confrontos com o Oriente.

Também com uma visão cética sobre as possibilidades que a Nova Ordem seria capaz de abrir, Hélio Jaguaribe (2008) se apoia em dados econômicos e na predisposição militar histórica dos Estados Unidos para demonstrar que a Pax Americana é insustentável, já que não tem capacidade de promover uma ordem estável, racional e justa. Com tal perspectiva, os anseios da humanidade ao final do 
século XX clamavam pela regulamentação internacional e sistemas institucionais de fato incapazes de serem sanados por uma gestão unipolar.

Uma visão conjugada das teses opostas aqui apresentadas aparece na abordagem do cenário de "polaridades indefinidas" por Lafer e Fonseca Jr. (1997, p. 55) que identificam dois momentos posteriores à Guerra fria. O primeiro enfático ao pensamento otimista é ilustrado pela atuação da ONU na operação Tempestade no Deserto que já mencionamos e aonde "a perspectiva era a de que se formavam, no mundo dos valores, grandes unanimidades". No segundo momento, os autores notam a depreciação desta linha de pensamento com a exacerbação dos nacionalismos, seja desencadeando ações bélicas ou em assuntos de ordem econômica, e evidenciam que a política internacional é motivada por "interesses, oportunidades, cenários favoráveis e outros valores, de origem predominantemente nacional, que se combinam, em alguns momentos para exprimir o sentido de sociedade que o sistema internacional também incorpora" (Lafer e Fonseca Jr., 1997, p. 60).

O estudo conduzido por Soares de Lima (1996) enfatiza a existência de convergências e heterogeneidades na Nova Ordem e vislumbra o mundo pós-1989 marcado pelo questionamento da primazia econômica norte-americana frente à ascensão de novos polos economicamente fortes tais como Europa e Japão; pelo estabelecimento do "compromisso liberal" que prega a liberalização comercial; e, pela perda da capacidade de barganha dos países periféricos em negociação com países desenvolvidos.

É então da bifurcação entre uma proposta universal e realidades particulares que as teorias de Relações Internacionais partem no período e se voltam tanto a prover explicações para o colapso da URSS como para mapear o papel dos Estados em geral e dos EUA em particular no novo contexto.

\section{A manutenção da abordagem política}

A despeito dos debates teóricos que ocorreram nas décadas anteriores entre Realistas e Liberais, nos anos 1990 ambos são vistos como parte da corrente positivista e seus estudos compartilham das seguintes características: utilização do racionalismo 
como metodologia de análise, visão materialista da política internacional e a transposição do ideal de natureza humana para o campo das Relações Internacionais. Assim sendo, seus estudos privilegiam a verificação das possibilidades de ordem, cooperação e ação coletiva neste contexto.

Com tal viés a corrente liberal aparece imbuída da superação de sua relação com o idealismo, obtida na década de 70 através da crítica a fungibilidade do poder ${ }^{8}$, a constatação de que há preponderância de questões econômicas nas agendas políticas e a utilização da teoria dos jogos para demonstrar a possibilidade de cooperação entre os atores (Keohane, 1984). Neste período, a escola se volta ao Institucionalismo neoliberal e aponta a possibilidade de cooperação entre os Estados a partir da proliferação de instituições e dos arranjos burocráticos por vezes materializados nas organizações internacionais.

Com tal óptica, aponta-se que cooperação interestatal parte do conflito de interesses e da impossibilidade de tratar temas como regulamentação econômica de modo isolado. Sendo assim as instituições ganham relevância na medida em que proveem canais de comunicação capazes de minimizar a desconfiança dos atores. Como colocam Martin e Simmons (1998, p. 743, tradução nossa) “Em uma estrutura de equilíbrio racionalista, esta afirmação é óbvia e inquestionável: os Estados escolhem e moldam as instituições. Os Estados o fazem porque enfrentam certos problemas que podem ser resolvidos através dos mecanismos institucionais" 9 .

Estudos desta natureza reconhecem a existência da anarquia no Sistema Internacional e apontam ainda que os arranjos de cooperação econômica podem mitigar a ocorrência de guerras, porem, não é esta a finalidade deles bem como não se descarta totalmente a possibilidade da emergência de conflitos. Como afirmam Keohane e Martin (1995, p. 43, tradução nossa) "frequentemente se nota que

\footnotetext{
${ }^{8}$ Sobre fungibilidade do poder, nos referimos ao rebate que os liberais fazem à tese de que o poder é empregável igualmente em qualquer situação de interesse prioritário para os estados mais fortes (Keohane, 1984).

${ }^{9}$ No original: "In a rationalist equilibrium framework, this statement is obvious and unexceptionable: states choose and design institutions. States do so because they face certain problems that can be resolved through institutional mechanisms" (Martin e Simmons, 1998, p. 743).
} 
assuntos militares e de segurança apresentam mais das características associadas à anarquia do que os de ordem político-econômica" ${ }^{10}$.

Outro foco analítico se volta para a relação entre a economia nacional e a economia mundial, bem como para a intersecção entre a Economia Política Internacional e o Institucionalismo neoliberal frente a internacionalização. Aqui a internacionalização é entendida como resultante de transações que permitem o fluxo de bens, serviços e capitais, que se dá através da uma dialética de reforço mútuo entre o crescimento do investimento, a desregulamentação e o desenvolvimento tecnológico.

$\mathrm{Na}$ abordagem de Keohane e Milner (1996) tanto a internacionalização como as instituições afetam as oportunidades e constrangem o enfrentamento de problemas econômicos e sociais pelos Estados. As consequências mais claras destes processos são o aumento da sensibilidade do mercado interno a tendências e choques externos e às pressões que a mobilidade do capital exerce sobre as legislações internas, capazes de gerar mais impactos do que a abertura comercial pura. Como as transações internacionais tem cada vez mais importância na economia mundial todos os países se veem compelidos a participar delas.

Em paralelo, é no ambiente doméstico que se define o grau de abertura à estes fluxos e as respostas que serão fornecidas às pressões econômicas externas, todavia dependentes da força das instituições nacionais e da permeabilidade delas à influências de grupos de interesse. Ou seja, o impacto da internacionalização é mediado pelo nível doméstico e neste sentido debates sobre comércio internacional, taxas de juros e investimento externo ficam cada vez mais evidentes nas pautas internas dos países, enquanto que a mesma pode mudar o interesse dos grupos e propiciar a formação de novas coalizões influentes nas políticas e instituições domésticas.

Já o viés realista contrapõe os pressupostos da teoria institucionalista ao enfatizar novamente a disparidade de ganhos dos atores e afirmar que o fim da disputa ente Leste $x$ Oeste não renega o papel de protagonista que a segurança

\footnotetext{
${ }^{10}$ No original: "it has often been noted that military-security issues display more of the characteristics associated with anarchy than do political-economic ones" (Keohane e Martin, 1995, p. 43).
} 
desempenha no cenário internacional, bem como vê nas instituições uma participa ção efêmera para a manutenção da paz. Sobre tal ponto Mearsheimer (1995, p. 47, tradução nossa) argumenta que "apesar do mundo não funcionar como as teorias institucionalistas dizem que ele funciona ou deveria, estar teorias aparecem como extremamente influentes tanto na academia como no mundo político" ${ }^{11}$. Segundo o autor, a valorização dos institucionalistas ocorre porque sua retórica é convergente aos elementos ideológicos da política dos EUA.

Como referência central do pós-Guera Fria aparece a defesa de Waltz (2000) ao neorrealismo com a afirmação de que as mudanças ocorridas no sistema não acarretam em mudanças de sistema e com isso defende que o fator constrangedor às unidades políticas mantém-se perene e é a anarquia. Em decorrência deste pensamento, a guerra continua sendo uma ameaça às nações que consequentemente devem perseguir suas políticas de poder e no decorrer do tempo estarão novamente estruturadas de forma a equilibrar suas capacidades bélicas. Mantendo a premissa de que o mundo multipolar é mais instável, o neorrealismo se posiciona de modo pessimista às projeções de paz e cooperação entre as grandes potências.

Do mesmo ponto parte Mastanduno (1997) com a argumentação de que tanto o equilíbrio de poder proposto pelos neorrealistas como o equilíbrio de ameaças ${ }^{12}$ definido pelo Realismo se mantém presentes na política externa dos EUA durante os anos 1990. Nesta análise o fim da bipolaridade confere mais espaço de manobra aos EUA que economicamente se orientam pela tentativa de contrabalancear a capacidade dos demais concorrentes fomentando a economia nacional e formando alianças enquanto em defesa optam pelo esforço de preservação de sua supremacia, através de uma política facetada em engajamento e contenção, capaz de manter a hierarquia internacional na área.

Outra proposta se presta ao estágio a que ficam restritos os Estado em desenvolvimento na política internacional e leva Escudé (1995) a formular, a partir da

\footnotetext{
${ }^{11}$ No original: "although the world does not work the way institutionalist theories say it does or should, those theories remain highly influential in both the academic and policy worlds" (Mearsheimer, 1995, p. 47).

$12 \mathrm{O}$ conceito de equilíbrio de ameaças é desenvolvido em: WALT, Stephen M. The Origins of Alliances. Ithaca, N.Y: Cornell University Press, 1987.
} 
experiência argentina, uma corrente teórica denominada como Realismo Periférico. Esta perspectiva indica que os pressupostos realistas de anarquia e de autonomia da esfera política sobre os demais assuntos não são aplicáveis à conduta dos países periféricos. Nestes casos, os Estados se guiam levando em conta uma hierarquia de poder no Sistema Internacional e a prioridade de concretizações em sua agenda econômica, sendo ambas capazes de limitar suas escolhas.

A partir destas constatações, advoga-se a necessidade de uma nova matriz de política internacional para os países da periferia norteada pela prudência na condução dos assuntos exteriores e na superação do subdesenvolvimento. Por esta visão o melhor curso de ação para integrantes do "mundo emergente" passa a ser (Escudé, 2009):

1- Alinhamento às políticas globais das potências;

2- Dedicação à promoção do desenvolvimento econômico;

3- Abstenção da política de poder, envolvimento em disputas entre as grandes potências e confrontação a potência hegemônica (salvo em questões materiais vitais);

4- Renúncia a políticas custosas com cunho normativo tais como a promoção da liberdade e da democracia;

5- Construção de uma memória histórica positiva do Estado capaz de The permitir opinar em assuntos internacionais.

Uma possível leitura do Realismo Periférico é a de que ele contradiz as principais formulações da Escola Realista, portanto, o seu "realismo" estaria calcado apenas na constatação da realidade com que se deparam as nações periféricas mas não expressa qualquer relação com as ideias que compõe a teoria realista de Relações Internacionais e se expressa fundamentalmente com as obras de Carr (2001), Aron (2002) e Morgenthau (2002).

Em relação ao Brasil, dois conceitos ganham força para interpretar e fundamentar a política externa que deveria ser adotada no período. O primeiro, proposto por Cervo (2008, p.51), considera que os anos 1990 foram marcados pela condução de uma inserção internacional brasileira que se caracterizou por uma "adaptação ao consenso regional e aos conselhos dos países centrais" em termos de pensamento e propósitos alinhados as ideias neoliberais. Cervo chama a fase de "Estado normal", isto é, a irrupção do paradigma neoliberal como motivador da 
supremacia do mercado e a retirada do Estado das atividades econômicas. Para o autor, este paradigma decorreu de impulsos externos - o colapso do socialismo, a vitória da economia de mercado e a globalização - e internos - crise do endividamento externos tomado na década de 1980 e recessão econômica advindos da fase anterior, desenvolvimentista.

Uma segunda interpretação parte de Leticia Pinheiro (2000) ao afirmar que no caso brasileiro a conjugação entre fatores internos e externos levou à adesão do "institucionalismo pragmático", ou seja, o engajamento nas instituições multilaterais que poderiam garantir maior presença do país no Sistema Internacional e maior acesso ao desenvolvimento e autonomia; porém, os arranjos de cooperação dos quais o país participava poderiam ter altos e baixos graus de institucionalização - medida em que o comportamento do ator de conforma dentro dos princípios e normas internacionais -, garantindo uma posição de liderança nos arranjos de baixa institucionalização, uma vez que a busca da autonomia era prioritária, sobrepondo, portanto, a relação custo/benefício aos princípios de justiça. Ou seja, a autonomia buscada por meio da participação na construção da ordem, garantiria legitimidade e imagem solidária, e, simultaneamente, a resistência ao aprofundamento da institucionalização, particularmente no âmbito regional, se fazia importante a fim de preservar o diferencial de poder do Brasil.

Também é parte da preocupação realista no período revitalizar o papel que os Estados ocupam no Sistema Internacional frente a um cenário de emergência de novos atores e de perda relativa do controle estatal sobre a agenda econômica e de defesa. Com este intuito, Slaughter (1997) argumenta que o ganho de poder por atores nãoestatais não necessariamente leva a perda de poder do Estado e que ambos são coexistentes sem possibilidades de substituição até porque as decisões internacionais são sujeitas às legislações e anseios populacionais internos.

Deste modo a analista emprega o termo transgovernamental para indicar que está ocorrendo uma reestruturação da burocracia estatal para lidar com os temas transnacionais e estabelecer acordos neste nível, o que fortalece o seu papel de instituição reguladora. Um ponto adicional suscitado em defesa do Estado é de que a 
própria organização democrático-liberal não está disposta a perder o controle de sua agenda em pró da governança global. Perspectiva semelhante é compartilhada por Sorensen (1998) que acredita que a globalização não desafia a sobrevivência dos Estados, pelo contrário, faz com que ele refine suas capacidades de resposta e seja imprescindível na criação de precondições internas que lhes possibilite plena inserção no modelo.

Em síntese, a abordagem positivista aponta aos Estados possibilidades de cooperação institucional, a dupla via entre políticas domésticas e internacionais, a manutenção do curso de ação das potências, uma possibilidade de atuação às nações periféricas e a incorporação de funções à burocracia estatal para lidar com os novos desafios e atores da cena externa. No que tange a política externa, vislumbram-se outros meios pelos quais as nações podem se fortalecer tais como a participa ção efetiva em regimes, o compartilhamento dos valores da potência e o empreendimento de ajustes internos para melhor tomar parte da realidade internacional.

\section{Uma proposta sociológica nas teorias}

O descontentamento com a centralidade exercida por análises que privilegiavam a política de poder durante a Guerra Fria abriu espaço para o debate com novas possibilidades analíticas calcadas em perspectivas sociais e culturais. É neste espectro que o construtivismo se consolida no campo das Relações Internacionais e apresenta a importância da identidade dos agentes, a constituição do interesse nacional e o papel das instituições como relevantes à política externa dos Estados.

Por considerar importante tanto o material como as ideias no terreno político esta corrente é vista como uma "via média" entre o racionalismo e perspectivas mais radicais como o reflexivismo ou o relativismo. Do mesmo modo, possui ramificações entre os próprios construtivistas que são frequentemente divididos, por exemplo, em 
moderados, críticos ou pós-modernos (Zehfuss, 2002). Para os propósitos do trabalho, serão apresentadas apenas as visões dos construtivistas moderados ${ }^{13}$.

Esta linha de pensamento se fundamenta nas reflexões sociológicas acerca da modernidade e afirma que a ideia intrínseca às sociedades industriais modernas é a de que o desenvolvimento tecnológico assegura a humanidade de que o progresso será contínuo, o que intersubjetivamente compele os indivíduos a pensarem dentro de determinados padrões (Guzzini, 2000). No entanto, a constituição das nações em desenvolvimento torna inegável que "o Sistema Internacional foi moldado de uma forma em que eles têm pouco a fazer com os princípios liberais, e que a estória do progresso econômico esqueceu muitas partes do mundo (Guzzini, 2000, p. 153, tradução nossa) " 14 .

Também é parte de sua ontologia o fim da bipolaridade, que pôde enfatizar a importância da ação humana nas estruturas e demonstrar as possibilidades de mudança no cenário externo. Segundo Adler (1999) o construtivismo é uma teoria social que questiona as bases epistemológicas em que se apoiam realistas e liberais ao tomarem a realidade como um dado e o racionalismo como única metodologia de trabalho. Com tais pressupostos, a perspectiva construtivista propõe a possibilidade de mudança, ainda que difícil, e o combate às estruturas conceituais dominantes no campo das Relações Internacionais.

Ao reconhecer a faceta intersubjetiva da política internacional, a corrente construtivista entende o poder de modo diferente dos racionalistas. Para eles o poder tem a função de reproduzir estruturas, disciplinar e policiar, sendo que as estruturas políticas são domínios em que os atores dividem impressões uns sobre os outros e que, portanto trabalham com a previsibilidade e a replicação de padrões em contextos específicos (Hopf, 1998).

\footnotetext{
${ }^{13}$ A expressão "construtivismo moderado" remete às perspectivas que buscam analisar os processos socia is pelos quais as identidades são construídas e as normas sociais desenvolvidas sem essencialmente Ihes criticar.

${ }^{14}$ No original: "The International System was ruled in a way which had little to do with liberal principles, and that the story of economic progress had forgotten several parts of the world" (Guzzini, 2000, p. 153).
} 
Para Wendt (1987) o comportamento social dos atores parte da relação entre os agentes e a estrutura, assim sendo os seres humanos e as organizações são atores propositivos cujas ações ajudam a reproduzir ou transformar a sociedade em que fazem parte, bem como a sociedade é constituída pelas ações sociais que estruturam as ações entre atores propositivos. Tais afirmações nos permitem ver os agentes e as estruturas como "codeterminantes" ou ainda como "entidades mutuamente constituídas".

Transpondo tal pensamento para o Sistema Internacional a pergunta central passa a ser "como devemos entender a construção social do sistema de Estados?"15 (Wendt, 2000, p. 174, tradução nossa). A resposta surge a partir da relação entre a identidade dos atores e a ação coletiva, a estrutura do sistema de estados é considerada intersubjetiva mais do que material e a identidade e os interesses estatais são em grande medida construídos por esta estrutura social e não criados de maneira exógena.

Com isso, Wendt (1999, p. 193 - 245) propõe que os Estados possuem identidades distintas de acordo com a seguinte tipologia:

1- Corporativa: capacidades físicas (ex. território, população)

2- Tipo: atrelada a questões domésticas (ex. democracia, parlamenta rista)

3- Papel: percebido pelos demais (ex. potência, Satélite)

4- Coletiva: combinada com as das demais nações

As relações interestatais atuam neste cenário como propulsoras das identidades do País e em última instancia orientam o comportamento dos demais, o que fortalece a busca dos atores por identidades sociais estáveis já que elas conferem previsibilidade nas relações com os outros. Outro ponto aqui destacado é que realidade material não é negada, mas só ganha relevância a medida em que atribuímos sentido e funções a objetos físicos.

Nestes termos, a questão da busca pela sobrevivência a partir de uma política de poder é vista como parte da identidade dos Estados e está apoiada sobre ideias, portanto, depende da visão dos atores para se constituir concretamente em situações

\footnotetext{
${ }^{15}$ No original: "How should we understand the social construction of the states system?" (Wendt, 2000, p. 174).
} 
de conflito ou cooperação. Ainda com tal concepção as identidades são formadas e determinantes para a concepção de anarquia desejada (Hobbesiana ou de inimigos, Lockeana ou de concorrentes e por fim, Kantiana ou de amigos) e os conceitos difundidos atuam como funcionais às práticas, bem como a transição entre os tipos de anarquia só pode ocorrer com a intensificação das interações entre os Estados. Nas palavras do autor: "o modo pelo qual os Estados satisfazem seus interesses materiais depende de como eles se definem em relação aos outros, o que é uma função das identidades sociais nos níveis doméstico e sistêmico de análise"16 (Wendt, 1994, p. 385).

Esta natureza de pensamento leva ao questionamento dos denominados interesses nacionais que para Adler (1999, p. 224) são "entendimentos intersubjetivos sobre o que se faz necessário para promover poder, influência e riqueza que sobrevivam ao processo político, dada a distribuição de poder e conhecimento em uma sociedade". Na mesma temática Finnemore (1996) considera que as redes transnacionais são capazes de alterar a percepção dos atores e afirma que os interesses dos Estados são definidos no contexto das normas e entendimentos internacionais que definem o que é bom e apropriado, o que torna a normatividade um ponto de influência sobre os tomadores de decisões.

Com isso, o principal papel das instituições é o de homogeneizar as percepções dos atores, aqui vistos como dispostos e maleáveis, no que tange a entendimentos subjetivos pontualmente delimitados e transmitidos pelos membros institucionais mais influentes. É importante ressaltar que esta perspectiva não desconsidera que as preferências são moldadas também por questões objetivas e pelas capacidades materiais dos Estados. Reside inclusive na disparidade entre demandas externas e condições internas a possibilidade de mau direcionamento da agenda, que por vezes incorpora medidas que não respondem a crises reais nem resolvem os problemas de modo eficaz (Finnemore, 1996).

\footnotetext{
${ }^{16}$ No original: "how a State satisfies its corporate interests depends on how it defines the selfin relation to the other, which is a function of social identities at both domestic and systemic levels of analysis." (Wendt, 1994, p. 385).
} 
A título de exemplo, a mesma obra trabalha na questão dos mercados que apesar de partirem de uma concepção moderna e vinculada ao Ocidente são parte de uma estrutura de organização social vista como legitima e que ganha um novo ponto de apoio quando se atribuí como um dos pontos que levou ao fim da URSS a falta de uma economia aberta.

Relacionando interesse e identidade dos Estados pode-se dizer que para sustentar seu reconhecimento coletivo, as nações aderem às normas e a partir do momento em que elas são compartilhadas os "Estados podem vir a subordinar seus interesses domésticos às aspirações internacionais" (Wendt, 1999, p. 231) ${ }^{17}$. Este fator ressalta que as instituições são limitadoras das escolhas dos agentes, seja abrindo novas possibilidades ou acentuando as disparidades de poder no momento da tomada de decisão (Onuf, 2002).

Apesar de seu caráter sistêmico estas preposições construtivistas podem ser utilizadas como ferramentas de análise de política externa e relações bilaterais entre países com poder díspares uma vez que sugerem um fator anterior à tomada de decisão, calcado na percepção dos atores envolvidos e no balizamento da equação entre o material e o intersubjetivo para a definição das agendas. Adicionalmente a perspectiva suscita discussões em torno da influência exercida pelo ambiente doméstico na política internacional.

\section{Revisitação às abordagens normativas}

O otimismo liberal do início da década de 1990 traz a volta dos estudos normativos para o campo das Relações Internacionais com base na crença de superação dos conflitos e da exacerbação do transnacionalismo, ambos agora levantados sob o rótulo de globalização.

Em seu aspecto mais amplo, a globalização é entendida como um processo que se expande sobre as esferas do Estado, da economia e da sociedade. Segundo Beck (1999) deste processo distingue-se o globalismo, entendido como uma faceta econômica que promove o mercado mundial e a ideologia neoliberal, e a globalidade,

17 No original: "States sometimes subordinate domestic to international concerns" (Wendt, 1999, p. 231). 
que permite a constituição de uma sociedade mundial sem governo o que significa "o conjunto das relações sociais que não estão integradas à política do Estado nacional ou que não são determinadas (determináveis) por ela" (Beck, 1999, p. 29).

Discussões sociológicas acerca da globalização destacam que este período corresponde à radicalização da modernidade e é capaz de intensificar as redes de relações sociais em nível mundial bem como conectar a realidade local de diferentes grupos sociais em todo o mundo (Giddens, 1991). Em caráter complementar, Castells (1999) infere que as redes são constitutivas de uma sociedade calcada na flexibilidade produtiva e na produção de conhecimento em grande escala, sendo que tais atributos acabam por interferir nas identidades sociais dos indivíduos.

Ao mesclar o pensamento liberal, o pensamento sociológico e fazer predições sobre o Sistema Internacional, os estudos normativos trazem o indivíduo para o centro das discussões e suportam a ideia de sociedade internacional. Nestas análises segue-se a definição de que a sociedade internacional existe em função das relações entre Estados e pode ter vários níveis, que vão desde um contato limitado até interações constantes com alto grau de institucionalização sustentada por normas e regras comuns, sendo que no pós-Guerra Fria ela fica mais próxima às caracterizações que se delineiam no segundo extremo (Jackson, 1995).

Sob o mesmo prisma Hoffmann (1990) sugere que a superação da bipolaridade permite o aprofundamento da cooperação e a coordenação de políticas ainda que eventualmente ocorram disputas entre as potências e finalmente, Hurrell (1999, p. 59) afirma que:

Com o fim da Guerra Fria, testemunhou-se uma expansão das ambições normativas da sociedade internacional. A globalização e as interconexões econômicas e humanas cada vez mais intensas entre as sociedades; a crescente gravidade das questões ecológicas; a democratização e as novas noções de legitimidade política; o aumento contínuo da quantidade de atores econômicos transnacionais e o surgimento de uma sociedade transnacional civil densa e crescentemente ativa.

O autor reitera a possibilidade de que haja valores compartilhados, mas debate a concepção de justiça em um cenário de desigualdade, em que a globalização desloca poder do Estado para o mercado e para as Instituições Internacionais. Assim sendo, a 
preocupação central é a de que ainda há um déficit institucional no plano externo que impõe limites à coerção assim como os valores podem criar novas formas de hierarquia.

Para superar tal panorama admite-se que a diversidade é uma característica da humanidade e não pode ser superada sem a separação entre questões de ordem e de justiça. A primeira não depende de valores éticos enquanto a segunda deve considerar diferentes perspectivas, já que o fato de normas mínimas não darem mais conta da realidade e das demandas sociais dos anos 1990 além de que estas se remetem aos próprios anseios da sociedade civil organizada em caráter transnacional (Hurrell, 2003).

Este discurso enfatiza a mudança de papel do Estado frente à globalização, que se mantém soberano ainda que perca autonomia espontaneamente para que o Sistema Internacional ganhe governança e paulatinamente mitigue a anarquia. Mesmo sem o estabelecimento do governo a governança é atribuída ao conjunto de normas e regimes que fazem com que na prática os Estados estejam "cada vez mais emaranhados em uma rede de interdependência e de arranjos regulatórios ou de colaboração, da qual geralmente não se podem livrar" (Zacher, 2000, p. 86).

Já pela abordagem de Held (1998, p. 13) há a crescente importância dos megablocos empresariais no cenário macroeconômico e as dificuldades impostas aos Estados em coordenar a economia, porem, a "globalização não deve ser assumida como uma representação nem do eclipse total do sistema de Estados ou a simples emergência de uma sociedade global" ${ }^{18}$. Com isso, enfatiza-se que formações históricas distintas impactam tanto na entrada das sociedades nos fluxos globais como nos impactos que sofrem com eles. Do mesmo modo acredita-se que a própria democracia pode ser afetada uma vez que há déficit de representatividade dos países nas Organizações Internacionais, agravados pelas disparidades de poder e pela impossibilidade de frear os efeitos das decisões.

Debruçando-se sobre as mesmas questões Brown (1995) parte de uma abordagem comunitarista para enfatizar que o compartilhamento de valores depende

\footnotetext{
${ }^{18}$ No original: "Global processes should not be assumed to represent either a total eclipse of the states system or the simple emergence of a global society" (Held, 1998, p. 13).
} 
da ocorrência anterior de práticas comuns. Logo, a formação de uma possível comunidade internacional depende de uma identidade compartilhada e indica que a emergência desta comunidade está calcada na ideia de progresso e não no altruísmo desinteressado e capaz de atingir a todas as pessoas do mundo. Também com uma postura crítica Herz (1997) indica que um dos motivos que revigora o debate sobre ética, moral e democracia é a possibilidade de racionalização e legitimação de políticas que correspondam aos interesses econômicos e geoestratégicos das potências Ocidentais.

Divergências nesta linha se dão pelo modo como devem ser implementadas as regras mas não se distinguem no que tange a relativização do papel estatal e do reconhecimento de que o ambiente internacional caminha para a obtenção de governança. A partir de tais preposições, o melhor curso de ação do Estado passa a ser o de intervir minimamente nos assuntos econômicos, já que não lhe cabe grande autonomia, assim como participar ativamente das instituições e considerar as perspectivas civis para que as normas sejam estabelecidas de modo substancial e convergentes aos anseios de sua população.

\section{A matriz ideológica: um ponto de contato}

Conforme apresentado, a década de 1990 foi palco do surgimento de diferentes correntes analíticas que vieram cobrir o déficit de explicações que eram capazes de fornecer as teorias com proposições universais e abstratas. A despeito de suas divergências estas vertentes acabaram por compor um aparato complementar de compreensão da ordem vigente durante o último decênio do século XX e por fim, abriram novos olhares para as relações interestatais e para a política externa.

Segundo a avaliação de Walt (1998) as fronteiras dos paradigmas de Relações Internacionais são permeáveis e deixam amplas oportunidades para arbitrariedade, de modo que a compreensão do objeto da área depende das contribuições de cada um deles. Na verdade o que se vislumbra ao estudar perspectivas teóricas é a possibilidade de elaboração de uma base para a investigação empírica e ao isolarem-se casos verificar qual delas fornecerá as respostas mais acuradas. Em uma ampla revisão, 
podemos afirmar que as teorias consolidadas neste período centralizam-se em três eixos de discussão: globalização, manutenção do Sistema Internacional Interestatal e configuração da ordem mundial.

O alargamento referido se deve ao reconhecimento do vasto campo de acontecimentos e dinâmicas que eram ignorados ou que só vieram à tona com o ruir da bipolaridade. Neste esforço vislumbra-se o início do desenvolvimento de teorias e conceitos próprios de nações ou regiões, por vezes não amplamente divulgadas por não estarem no centro do poder econômico e estratégico, mas que apresentam contribuições substantivas para mostrar significados do que ocorre no plano real e por demonstrarem a interlocução entre a esfera doméstica e externa na política internacional. Com isso, também a funcionalidade das teorias pode ser revista e fatores como o local e a época de produção podem ser tratados como variáveis importantes (Lechini, 2009).

Pelo cenário aqui descrito, nota-se que mesmo com projetos distintos todas estas correntes estão imbuídas do pensamento liberal, resgatado pelo reconhecimento da supremacia da economia de mercado e das instituições, aonde a sociedade é o eixo político central, múltiplos atores são reconhecidos e as preferências dos Estados por vezes são mais importantes do que seus recursos de poder, o que infere um guia de escolha normativa, ou seja, prega o senso do que é bom. Tal pensamento atua como eixo norteador das teorias no pós-Guerra Fria que também concebem o otimismo, comum a épocas pós-conflito, para ofuscar questões de segurança e tratarem majoritariamente da agenda econômica. Implicitamente, prescrevem um curso de ação para os Estados capaz de apoiar estes ideais e com isso legitimam a vitória dos EUA.

É inviável negar que há uma carga propositiva implícita no conjunto teórico trabalhado que por vezes sugere o questionamento da primazia estadunidense e até mesmo identifica componentes do Sistema Internacional mais importantes que os Estados, mas que ainda assim operam sobre os mesmos pressupostos ideológicos. Outro ponto de atenção é que ao darem mais ênfase às questões econômicas, naturalmente as discussões permeiam a disposição dos atores e o ordenamento de 
poder em uma estrutura de livre mercado, ou seja, não se delimita um ponto de inflexão ou alternativo para a arena política.

De acordo com Andrew Hurrell (2009), o liberalismo dos anos 1990 ocorreu tanto como modelo de análise das relações internacionais, como enquanto programa político. As perspectivas liberais se consolidaram no contexto das relações entre os Estados enfatizando a densidade da interdependência social, econômica e ecológica entre os países, o consenso ideológico em torno da crença no livre comércio e nos valores democráticos, a emergência de novos atores transnacionais, a pluralidade de atores na formulação da política externa e a crescente importância das instituições tanto regionais como multilaterais. $\mathrm{O}$ autor ainda explica que é central ao liberalismo a visão de que "a democratização muda os objetivos e as prioridades da política externa dum país e, em particular, amplia a possibilidade de cooperação com outras democracias, tanto global como regionalmente" (Hurrell, 2009, p.173).

Novamente, este consenso em torno de algumas premissas recolocou parâmetros de atuações baseados na realidade social da potência internacional como sendo universalmente representativa e ajudou a esvaziar as alternativas dos países em desenvolvimento, que quanto mais próximas aos EUA mais eram seduzidos por suas propostas, de modo que sua maior influência manteve-se no bloco Ocidental.

\section{Referências bibliográficas}

Adler, Emanuel. 2011. "O construtivismo no estudo das relações internacionais. " Lua Nova,

São Paulo, n. 47, Ago. $1999 . \quad$ Disponível em: $<$ http://www.scielo.br/scielo.php?script=sci_arttext \&pid=S0102-64451999000200011\&lng=en\&nrm=iso >. Acesso em $25 \mathrm{Jul}$.

Aron, Raymond. 2002. Paz e guerra entre as Nações. Brasília: Editora Universidade de Brasília / IPRI; S. Paulo: IOESP.

Arrighi, Giovanni. 1996. O longo século XX: dinheiro, poder e as origens do nosso século. São Paulo: UNESP.

Baillard, Philippe (Org.). 1990. Teoria das relações internacionais. Tradução de J.J. Pereira Gomes e A. Silva Dias, Lisboa: Fundação Calouste Gulbenkian.

Beck, Ulrich. 1999. O que é globalização? Equívocos do globalismo respostas a globalização. São Paulo: Paz e Terra. 
Bobbio, Norberto. 1995. Direita e esquerda. São Paulo: UNESP.

Brown, Chris. 1995. "International Political Theory and the idea of world community." In: Booth, Ken; Smith, Steve (Orgs.). International theory today. London: Polity Press.

Carr, Edward Hallett. 2001. Vinte anos de crise: 1919-1939. Brasília: Editora Universidade de Brasília / IPRI.

Castells, Manuel. 1999. A Sociedade em rede. São Paulo: Paz e Terra.

Cervo, Amado. 2008. Inserção internacional: formação dos conceitos brasileiros. São Paulo: Saraiva.

Cox, Robert. 1986. "Social forces, States and World Orders beyond international relations theory." In: Keohane, Robert (Org.). Neorealism and its critics. New York: Columbia University Press.

Cox, Robert e Sinclair, Timothy. 1999. Approaches to world order. Cambridge: Cambridge University Press.

Duroselle, Jean-Baptiste. 2000. Todo império perecerá: teoria das Relações Internacionais. Tradução de Ane Lize Spaltemberg de Seiqueira Magal hães, Brasília: Editora Universidade de Brasília.

Escudé, Carlos. 1995. El Realismo de los Estados Débiles. Argentina: Grupo Editor Latinoamericano.

Escudé, Carlos. 2009. "Peripheral Realism: an argentine theory-building experience 1986 1997." In: Saraiva, José Flávio Sombra (Org.). Concepts, history and Theories of international relations for 21st Century: regional and national approaches. Brasília: Premius, Instituto brasileiro de relações internacionais.

Finnemore, Martha. 1996. National interests in international society. New York: Cornell University Press.

Fukuyama, Francis. 1989. "The end of history?" The National Interest, v. 16, pp. 3-18, Summer.

Fukuyama, Francis. 1999. "Second thoughts: the last man in a bottle." The National Interest, pp. 1-20, Summer.

Giddens, Anthony. 1991. As consequências da modernidade. Tradução de Raul Fiker. São Paulo: UNESP.

Guzzini, Stefano. 2000. "A Reconstruction of Constructivism in International Relations." European Journal of International Relations, v. 6, n. 2, pp. 147-182.

Halliday, Fred. 1994. "A Guerra Fria e seu fim: consequências para a teoria das Relações Internacionais", Contexto Internacional, v. 16, n. 1, pp. 53-73, jan/jul.

Halliday, Fred. 1995. "International Relations and Its Discontents", International Affairs, v. 71, n. 4, pp. 733-746.

Held, David. 1998. "Democracy and globalization." In: Archibugi, Daniele; Held, David; Kohler, Martin (Orgs.). Re-Imagining political community: studies in cosmopolitan democracy. Cambridge: Polity Press. 
Herz, Mônica. 2011. "Teoria das Relações Internacionais no Pós-Guerra Fria." Dados, Rio de Janeiro, v. 40, n. 2, 1997. Disponível em <http://www.scielo.br/scielo.php?script=sci_arttext \&pid=S0011-52581997000200006\&lng=en\&nrm=iso >. Acesso em 18 Aug.

Hoffmann, Stanley. 1990. "A New World and Its Troubles." Foreign Affairs. v. 69, n. 4, pp. 115122, Fall.

Hopf, Ted. 1998. "The promise of constructivism in International Relations." International Security. v. 23, n. 1, pp. $171-200$, Summer.

Huntington, Samuel. 1993. "The Clash of Civilizations?" Foreign Affairs. v. 72, n. 3, pp. 22-49, Summer.

Hurrell, Andrew. 1999. "Sociedade Internacional e governança global." Lua Nova. n. 46, pp. 55 -75 .

Hurrell, Andrew. 2003. "Order and justice in International Relations: what is a stake?" In: Foot, Rosemary; Gaddis, John Lawis; Hurrell, Andrew (Orgs.). Order and justice in international relations. Oxford: Oxford University Press.

Hurrell, Andrew. 2009. "O Brasil e os Estados Unidos: reflexões comparativas." In: Hirst, Monica. Brasil-Estados Unidos: desencontros e afinidades. Rio de Janeiro: Editora FGV.

Ikenberry, John G. 1996. "The myth of post-cold war chaos." Foreign Affairs. v. 46, n. 3, pp. 79 -91 , mai / jun.

Jaguaribe, Hélio. 2008. “A nova odem mundial." In: Dupas, Gilberto; Lafer, Celso; Lins da Silva, Carlos Eduardo (Orgs.). A nova configuração mundial do poder. Brasília: Paz e Terra, p. 23-37.

Jackson, Robert H. 1995. "The Political Theory of International Society." In: Booth, Ken; Smith, Steve (Orgs.). International Relations theory today. Pennsylvania: State University Press.

Kennedy, Paul. 1989. Ascensão e queda das grandes potências: transformação econômica e conflito militar de 1500 a 2000. 2. ed. Rio de Janeiro: Elsevier.

Keohane, Robert. 1984. After hegemony: cooperation and discord in the world political economy. Princeton: Princeton University Press.

Keohane, Robert e Martin, Lisa. 1995. "The Promise of Institutionalist Theory", International Security, v. 20, n. 1, pp. 39-51.

Keohane, Robert e Milner, Helen. 1996. "Internationalization and domestic politics: an introduction." In: Keohane, Robert \& Milner, Helen (Orgs.). Internationalization and domestic politics. Cambridge: Cambridge University Press.

Kissinger, Henry. 2004. Diplomacy. New York: Touchstone.

Lafer, Celso e Fonseca Jr., Gelson. 1997. "Questões para a diplomacia no contexto internacional de polaridades indefinidas: notas analíticas e algumas sugestões." In: Fonseca Jr., Gelson; Nabuco de castro, Sérgio Henrique (Orgs.). Temas de política externa brasileira II. V. 1, 2. ed. Brasília: Fundação Alexandre de Gusmão, São Paulo: Paz e Terra.

Lechini, Gladys. 2009. "Africa, Asia and Latin America: the building of concepts to international relations in global south (a view on some international reports)." In: Saraiva, José Flávio 
Sombra (ed.). Concepts, histories and theories of international relations for the 21st century: regional and national approaches. Brasília: Premius, Instituto brasileiro de relações internacionais.

Martin, Lisa e Simmons, Beth. 1998. "Theories and empirical studies of international institutions." International Organizations, v. 52, n. 4, pp. 729-757.

Mastanduno, Michael. 1997. "The unipolar moment: realist theories and U.S. grand strategy after the Cold War." International Security, v. 21, n. 4, pp. 49-88.

Mearsheimer, John. 1995. "The false promise of international institutions", International Security, v. 19, n. 3, pp. 5-49, Winter.

Morgenthau, Hans. 2002. Política entre as Nações. Brasília: Editora Universidade de Brasília.

Nye Jr, Joseph. 2002. O paradoxo do poder americano. São Paulo: UNESP.

Onuf, Nicholas. 2002. "Institutions, intentions and international relations", Review of International Studies, v. 28, n. 2, pp. 211-228.

Pinheiro, Letícia. 2000. "Traídos pelo desejo: um ensaio sobre a teoria e a prática da política externa brasileira contemporânea. "Contexto Internacional. Rio de Janeiro, vol. 22, n.2, jul/dez, p.305-335.

Silva, André Luis Reis da. 2008. Do otimismo liberal à globalização assimétrica: a política externa do governo Fernando Henrique Cardoso (1995-2002). Tese de doutorado em Ciência Política. Universidade Federal do Rio Grande do Sul, Porto Alegre.

Slaughter, Anne-Marie. 1997. "The real new world order." Foreign Affairs, v. 76, n. 5, pp. 183 197, set/out.

Soares de Lima, Maria Regina. 2009. "Teses equivocadas sobre a ordem mundial pós-Guerra Fria." Dados, Rio de Janeiro, v. 39, n. 3, 1996. Disponível em $<$ http://www.scielo.br/scielo.php

?script=sci_arttext\&pid=S0011-52581996000300005\&Ing=en\&nrm=iso>. Acesso em 02 Set.

Sorensen, Georg. 1998. "IR theory after cold war." Review of International Studies. pp. 83 100 , v. 24, ,n.5.

Todd, Emmanuel. 2003. Depois do império: a decomposição do sistema americano. Tradução de Clóvis Marques, Rio de Janeiro: Editora Record.

Vizentini, Paulo G. F. 1996. A nova ordem global: relações internacionais do século 20. Porto Alegre: Editora da Universidade / UFRGS.

Walt, Stephen. 1998. "International Relations: one world, many theories." Foreign Policy. Special Edition: Frontiers of Knowledge, n. 110, pp. 29-46, Spring.

Waltz, Kenneth. 1979. Theory of International Politics. New York: McGraw-Hill.

Waltz, Kenneth. 2000. "Structural Realism after the Cold War", International Security, v. 25, n.1, pp. 5-41.

Wendt, Alexander. 1987. "The agent-structure problem in international relations", International Organization. v. 41, n. 3, pp. 335-370. 
Wendt, Alexander. 1994. "Collective identity formation and the international state." American Political Science Review June. v. 88, n. 2, pp. 384-396.

Wendt, Alexander. 1999. Social theory of international politics. United Kingdom: Cambridge University Press.

Wendt, Alexander. 2000. "On the via media: a response to the critics." Review of International Studies. v. 26, n.1, pp. 165-180.

Zacher, Mark. 2000. "Os pilares em ruína do templo de Vestfália: implicações para a governança e a ordem internacional." In: Rosenau, James; Czempiel, Ernst-Otto (orgs.). Governança sem governo: ordem e transformação na política mundial. Brasília: Editora Universidade de Brasília.

Zehfuss, Maja. 2002. Constructivism in international relations: the politics of reality. United Kingdom: Cambridge University Press. 